\title{
De Japón para el mundo: consumo y percepción de las jóvenes otakus mexicanas
}

\author{
From Japan to the world: consumption and perception of young Mexican \\ otakus
}

\author{
Fátima Itzel GARCíA NOYOLA \\ Universidad Autónoma de San Luis Potosí \\ fatimaitzelgarcia12@gmail.com \\ María A. GABINO CAMPOS \\ Facultad de Ciencias de la Comunicación \\ Universidad Autónoma de San Luis Potosí
}

Recibido: 16 de junio del 2016 Aceptado: 27 de septiembre 2016

\begin{abstract}
Resumen
El fenómeno otaku ha ido permeando poco a poco. El anime y la manga forman parte de los consumos culturales de la mayor parte de los jóvenes en el mundo. Ya se distingue entre el aficionado otaku japonés y el globalizado o Akiba Kei. Con este trabajo, se buscó un acercamiento al significado y consumo de los productos de la industria cultural japonesa por parte de jóvenes mexicanos, para lo cual se realizaron entrevistas semiestructuradas a 10 jóvenes que se acuñaron como otakus mexicanos.

El análisis proporciona indicios de que en México, este placer por lo japonés ha generado una identidad grupal o tribu urbana y se desecha la idea del otaku como un inadaptado social ya que es con sus iguales con quienes comparte sus gustos.

De igual manera, la identidad de los otakus se forja a través de los personajes de las animaciones japonesas, así como las ideas y modas pertenecientes a una la cultura japonesa.
\end{abstract}

\section{Abstract}

The otaku phenomenon has been permeating little by little. Anime and manga are part of the cultural consumptions of most young people in the world. A distinction is already made between the Japanese otaku fan and the globalized one or Akiba Kei. With this work, an approach was sought to the meaning and consumption of the products of the Japanese 
cultural industry by young Mexicans, for which semi-structured interviews were conducted with 10 young people who were coined as Mexican otakus. The analysis provides indications that in Mexico, this pleasure for the Japanese has generated a group identity or urban tribe and the idea of the otaku as a social misfit is discarded since it is with his peers that he shares his tastes. In the same way, the identity of the otakus is forged through the characters of the Japanese animations, as well as the ideas and fashions belonging to a Japanese culture.

Palabras clave: Anime, animaciones japonesas, cultura otaku, México.

Keywords: Anime, Japanese animations, otaku culture, Mexico.

\section{Introducción: El anime y el manga: consideraciones básicas para un mejor entendimiento}

Hablar de Japón es hablar de uno de los países de mayor reconocimiento en el mundo. No solo por sus costumbres o avances tecnológicos, sino también por ser uno de los países con mayor impacto internacional gracias a la distribución de sus producciones auditivas y visuales: películas, videojuegos, animaciones y mangas. Estas últimas son las que han tomado gran importancia a partir de su distribución a nivel internacional.

La industria del anime y el manga surge de manera más redituable a partir de los setenta con la internacionalización de dichos productos. Gracias a la exportación de títulos como Astro Boy, Mazinger $Z$, entre muchos otros, esta industria comienza a llamar la atención del público de todas las edades, por contener tramas diferentes a las caricaturas occidentales.

Antes de continuar es necesario conocer la definición de ambos términos:

Anime (アニメ) es el término occidental con que se conoce a la producción de dibujos animados o caricaturas para televisión hechos en Japón. La palabra también engloba a las producciones hechas directamente para DVD llamadas OVA u OAV (original animation video) y películas animadas para cine. (Cobos, 2010). 
Manga: (漫画) es la palabra japonesa con que se conoce en el contexto occidental a las tiras cómicas, historietas o cómics hechos en este país. Traduce literalmente "dibujos caprichosos" o "garabatos" y quienes lo dibujan reciben el nombre de mangaka. (Cobos, 2010).

Ambos productos han resultado ser industrias bastante lucrativas para Japón, según un estudio de la Organización Japonesa de Comercio Exterior en el 2001, tuvo por ingresos de la industria japonesa de animación (filmes, videos y producciones) unas ganancias de más de 17 mil millones de dólares. (Cobos, 2010).

De igual manera, el manga se mantiene en el gusto del público consumidor a nivel internacional según Jiménez (2006): “...Japón es actualmente el mayor productor de cómics. Su difusión disparada a través de los primeros trabajos... nunca ha dejado de ser masiva... Apoyado en una estrecha conexión con el anime... su consumo sigue siendo eminentemente popular..." (En Balderrama y Pérez, 2009)

Una de las características principales del anime y manga es la diversidad de temáticas abordadas en sus historias; no están dirigidas a un solo público sino que, por el contrario, de acuerdo al tipo de temas que se tratan, el género y la edad al público que vaya dirigido relatará situaciones acordes.

Algunos de los géneros en los que se dividen son:

- Shojo: género dirigido al público joven femenino.

- Shonen: género dirigido al público masculino joven, se caracteriza por tener historias con acción.

- Kodomo: género dirigido a los niños

Es necesario destacar que cada uno de estos géneros también posee subgéneros y combinaciones de los mismos lo que permite mayor amplitud de temas así como intereses 
de personas con edades cercanas o muy distantes, pero unidas por un gusto (objetivo) específico.

\section{Se escribe la historia en México}

Es en los años setenta cuando las animaciones japonesas llegan a nuestro país, introduciendo títulos como Heidi, Princesa Caballero, Candy Candy, Meteoro, etc. Es hasta 1990 que se puede hablar de un impacto y consumo en la sociedad mexicana gracias a la emisión de series como Caballeros del Zodiaco, Ranma 1⁄2, Dragon Ball, Súper Campeones, Sailor Moon y Las Guerreras Mágicas (Cobos, 2010).

Aún cuando estas series se dieron a conocer hace mucho más tiempo, es hasta 1996 cuando se empiezan a utilizar los términos de anime y manga para referirse a las animaciones y cómics japoneses respectivamente.

En 1998 comienza una batalla entre televisoras mexicanas, TV Azteca y Televisa, ya que mientras TV Azteca estaba en el proceso de eliminación gradual de los "animes" en su programación, Televisa comenzaba a incluir una nueva barra con más variedad, pero siempre dirigida a los jóvenes y niños, destacando: Hamtaro, Doremi, Mirmo Zibang, Inuyasha, Dragon Ball, entre muchos otros.

En 2009 la transmisión de animaciones japonesas en canales de televisión mexicana abierta se vuelve inexistente, son los canales de pago quienes se encargan de su transmisión y distribución en diversas partes de América Latina.

Con el desarrollo y expansión de internet la distribución del anime alcanza otra etapa, ya que la digitalización y la nueva forma de comunicación proporciona su expansión y conocimiento alrededor del mundo. Internet brinda el acceso, a noticias, títulos, capítulos, música y todo aquello relacionado con la salida de alguna serie, de manera gratuita, situación que genera un nuevo mercado. 
La comercialización de estas producciones se convirtió en un negocio muy redituable, al igual que la introducción de productos originales asociados a estas, a nivel internacional, lo que permitió a los fanáticos y coleccionistas obtener de manera rápida y sencilla objetos que en un principio parecían imposibles de conseguir.

La propagación del mercado dio paso a la expansión de una ideología, asimismo, se conoció más toda la oferta cultural relacionada con Japón, lo que posibilitó el crecimiento de los aficionados en el anime y la cultura nipona en general. El aumento de los fans por esta cultura posibilitó el surgimiento de un nuevo grupo o tribu urbana, que si bien es cierto, sus inicios se dieron en 1996, es en el 2000 cuando se dan a conocer debido a las prácticas que realizaban y que en ese entonces, salían de lo "común".

\section{Cultura del anime-cultura otaku: enfoque teórico}

Según Balderrama y Pérez (2009), la cultura se refiere a una serie de creencias, valores, costumbres y prácticas compartidas por un agregado dado de individuos. Al definirse la cultura como compartida por un grupo de individuos, es entonces un elemento capaz de distinguir significativamente a un grupo social de otros.

Los otakus plasman a través de sus prácticas aquello en lo que creen, pero van más allá porque manifiestan en diversas formas y en lugares específicos su filiación cultural, con lo que se puede decir que ya cuentan con una organización clara y evidente, característica de lo que se conoce como tribu urbana.

Las tribus urbanas son grupos de jóvenes que se han auto dotado de formas organizativas que actúan hacia el exterior en relación con los demás y que se protegen ante la exclusión de los otros y que por lo tanto crean espacios de pertenencia e identidades a partir de las cuales se genera un sentido en común sobre un mundo incierto (Reguillo, 2000). 
El otaku tiene connotaciones diferentes alrededor del mundo según el país en el que nace. En Japón, otaku se refiere a la persona que dedica tiempo y dinero en un pasatiempo determinado, por lo cual su estancia en el hogar es reducida y comúnmente solo abandona esta para las necesidades más básicas. Otra manera para designar a los fanáticos japoneses en su país es Hikikomori que hace referencia a las personas apartadas, recluidas, "aisladas de la sociedad" que han perdido el interés por llevar una vida social debido al grado de atención que dedican a sus pasatiempos. Aunque este término es comúnmente utilizado para señalar a un grupo social que sufre distintos trastornos como fobia social, ansiedad social, agorafobia, trastorno de personalidad e incluso timidez extrema.

Por su parte, el otaku globalizado difiere del oriental en aspectos destacables y notorios. Mientras que el otaku japonés es un fanático generalizado, sin un hobbie en específico, en occidente es una persona con inclinaciones en gustos y preferencias a el manga y el anime japonés.

El otaku puede llamarse también Akiba kei, término que pierde las connotaciones negativas. Esta referencia significa literalmente "estilo Akihabara", haciendo alusión al distrito comercial japonés que distribuye lo último en tecnología, anime, manga y videojuegos.

Tanto en Japón como en el resto del mundo, el otaku es un seguidor ávido del manga y el anime, objetos culturales alrededor de los cuales se erige su identidad. En Occidente, dicha identidad se forja a través de la interacción real o virtual entre fans del otaku, individuos que comparten dicha afición y los cuales, más adelante, pueden construirse como grupos otakus (Balderrama y Pérez, 2009, p. 27).

Suele señalarse esta ideología como un fanatismo negativo y enfermizo que orilla a quien es parte de ella a sumergirse en un mundo ajeno a su persona, costumbres, lugar de origen, etc., sin embargo, parte de la tendencia del otaku globalizado es el desdeño por todo aquello que amenaza con romper esa cultura propiamente ideada, la cual se ha fraguado a 
base del consumo de los anime, manga y videojuegos que este consume (Balderrama y Pérez, 2009).

Se conocen distintos términos para referir a los fanáticos en base al pasatiempo que estos llevan a cabo, destacando:

- Anime otaku: Fanático del anime.

- Manga otaku: Fanático del manga.

- Geemu (game) otaku: Fanático de los videojuegos.

- Visual otaku: Fanático de vestimentas de personajes ficticios.

- Wota otaku: Fanático de Idols (cantantes o grupos famosos).

- Mekey otaku: Fanáticos del aprendizaje sobre manga y animes, así como de los autores, historia, costumbres, etc.

Algunas características adjudicadas a los otakus globalizados suelen ser la inadaptación social, fanatismo irracional, introversión, aislamiento, entre otras. Por lo general, existe un polo opuesto de estas características que pueden ser observadas al analizar el estilo de vida que este grupo social desempeña; por ejemplo: la inadaptación social suele quedar de lado al considerar a los otakus como un grupo social, puesto que el aislamiento y la reclusión se oprimen en la búsqueda del fanático por reafirmar su identidad, así como la del grupo que este representa.

\subsection{El otaku mexicano}

En México, es común que las personas ajenas a la cultura otaku llamen "frikis" a quienes son gustosos de la cultura japonesa y sus producciones, esto haciendo referencia al término inglés freak cuyo significado es 'raro', por lo tanto friki: 'rarito'. Es necesario comprender que rarito hace referencia a todas las cosas y personas poco comunes, que resaltan y se distinguen de los demás, ya sea por sus gustos, vestimenta, indumentaria, maquillaje o cualquier cosa extraña o diferente. Es por esto que el otaku mexicano es gustoso y se siente orgulloso de serlo, le disgusta que lo confundan con otros, integrantes de otra cultura juvenil, a quienes también se les considera rarito. 
Dentro de las características más importantes para las culturas urbanas y por ende, para la cultura otaku se encuentran: la estética y el espacio. Es en la estética (maquillaje, vestimenta, accesorios, etc.), donde se crean los personajes, en donde se distinguen de quiénes son y quiénes quieren ser. Según Reguillo (2000), estos patrones estéticos también permiten identificar y diferenciar a sus iguales. Por su parte, el espacio "es el lugar donde desarrollan aquellas actividades que los identifican como grupo... Es donde exaltan sus gustos y preferencias y en donde se crean una identidad individual y grupal" (Reguillo, 2000, p. 112). Ambos factores son generadores de la identidad individual y grupal que los otakus se van forjando a través del tiempo.

Tal como lo plantea Reguillo (1991), la identidad es "una relación objetiva que se establece entre su portador y el medio en donde se desenvuelve, una plataforma desde la cual se interactúa con los demás." Esta identidad, para los jóvenes pertenecientes a la cultura otaku, refleja esa probable necesidad por salir de los cánones establecidos por la sociedad. Por consiguiente, "es posible distanciarse de la tradición y elegir entre varias posibilidades, nuevas y valiosas identidades de la oferta circulante en el escenario social" (Margulis et al., 1998, p. 198).

Por tanto, si se hablar de identidad, se debe incluir el resto de grupos y roles externos del otaku por los cuales se ve influenciado, como son el entorno escolar, familiar, amistoso o de trabajo. El otaku aprende a desempeñarse sin negar las preferencias que lo caracterizan (Balderrama y Pérez, 2009, p. 53).

Estas interacciones entre actores pertenecientes y ajenos al grupo, enmarcan los lugares, sus territorios, en los cuales se pueden desarrollar las prácticas que los hacen ser diferentes a los otros e identificados por sus iguales. Aquel espacio o escenario donde el maquillaje, la ropa y los accesorios cobran su verdadero significado, su habitat, es decir, aquel espacio en el que se muestran tal cual son. 
Para la cultura otaku no existe un espacio físico en el que se desarrollan las prácticas de diferenciación sino que las llevan a diferentes escenarios y momentos en los que comparten sus aficiones por el manga y el anime (y en general por todos los productos japoneses). Dichos escenarios se crean por consenso entre los integrantes del grupo o a través de reuniones en mayor escala que abarcan diversos mercados tales como la música, la comida y por supuesto, los animes y mangas. Estas reuniones, además, permiten el intercambio cultural e ideológico, tienden a ser públicas y se denominan: convenciones.

Otros sitios de intercambio y consumo son los espacios públicos que se dedican a la venta de artículos tecnológicos y relacionados con la oferta de productos japoneses exclusivos y del continente asiático en particular.

Tanto en las convenciones como en los puntos de venta, los productos ofertados tienen rangos de precios variados, dependiendo de la accesibilidad que dichos productos tengan así como la demanda que pueda existir entre sus aficionados.

En México, un artículo original de cualquier tipo oscila entre los 300 y 1000 pesos (aprox. 1 Dólar $=20.091$ Pesos), mientras que las falsificaciones tienen precios relativamente bajos. Para los otakus, el precio no es una limitante. Obtener artículos originales de algún anime, grupo o manga cobra más importancia y valor simbólico para ellos y entre sus pares.

Por lo tanto, un otaku mexicano no es solo un consumidor de producciones audiovisuales niponas, es también un productor de ideas, estilos y costumbres adaptadas al lugar y tiempo en el que viven, por lo que, para poder entender cómo se perciben en lo individual y lo social, es necesario entender de dónde surgen su afición y sus hábitos.

A partir de estas ideas, se planteó esta investigación con el objetivo de conocer la percepción del otaku mexicano de su realidad e identidad.

\section{La percepción del otaku mexicano en su propia voz. La metodología}

Facultad de Ciencias Políticas, Sociales y de la Comunicación Universidad de La Laguna Avenida César Manrique, s/n; Campus de Guajara 38071 La Laguna, Tenerife (Islas Canarias - España) 
El estudio de la autopercepción del otaku mexicano se planteó desde una perspectiva cualitativa y para ello se diseñó una entrevista semiestructurada. Las preguntas del cuestionario se categorizaron desde lo general a lo particular, es decir, desde situaciones de índole social hasta aquellas de carácter personal.

A continuación, se muestra la tabla de las categorías en la que se fundamentó el cuestionario:

Tabla 1 Categorías del cuestionario

\begin{tabular}{ll}
\hline Gustos e intereses & $\begin{array}{l}\text { Social } \\
\text { Individual }\end{array}$ \\
\hline Pertenencia e identificación & Social \\
& Individual \\
& Social \\
Consumo & Individual \\
& Medios \\
\hline
\end{tabular}

Fuente: Elaboración propia.

La población sobre la cual se aplicó la entrevista fue jóvenes mexicanos pertenecientes al estado de San Luis Potosí que se autodefinen como otaku. De todos ellos, número difícil de definir debido la heterogeneidad de dichos seguidores, se tomaron como sujetos de estudios, siguiendo criterios de accesibilidad, 10 jóvenes (género femenino) de entre 20 y 25 años de edad que se declararon otakus y, por ende, se consideran pertenecientes a esta cultura. Esto permitió ahondar sobre la permeabilidad que ha tenido la cultura japonesa y sus producciones dentro de sus vidas.

Cabe destacar que se delimitaron los sujetos de estudios (a partir de ahora para las entrevistadas) a través de la técnica de bola de nieve, gracias a las interacciones que se 
tuvieron con algunos de los sujetos de estudio así como a través de personas que conocían a quienes cumplían con las características necesarias para formar parte del estudio. De hecho cuatro de las entrevistadas pertenecían al mismo club y fue así como se conocieron, y como se logró la inclusión en nuestro estudio.

Con respecto a la actitud de los sujetos, mencionar que presentaron apertura a las preguntas y disposición a ser cuestionados sobre sus gustos; se mostraron cómodos al hablar el tema y expresaban sus pensamientos lo que de alguna manera dejaba ver que estaban acostumbradas a hablar sobre dichos gustos.

\section{Resultados}

De acuerdo con las entrevistas realizadas todas las personas entrevistadas gustan de las producciones japonesas en cualquiera de sus presentaciones (animes, películas, videojuegos, música, manga, e incluso literatura). El sujeto 2 describió como se inició:

al ingresar en la cultura otaku comienzas viendo animes porque te los recomiendan o porque quieres recordar algo que de pequeño viste, pero también sucede que comienzas a interesarte más por otras cosas como la música o los libros. En mi caso así pasó, busco cosas para leer que tengan que ver con Japón y su cultura en general... (Sujeto 2)

Dentro de la parte de inserción a los animes y a la cultura asiática, 8 de las 10 personas entrevistadas aseguraron haber comenzado su gusto por el anime desde pequeñas gracias a la transmisión que existía por la televisión abierta (televisión gratuita) en los años noventa. Cuando ya no se transmitían por la televisión abierta, siguieron buscando producciones japonesas y con el tiempo encontraron otros títulos y personas con las que podían compartir su afición. Las otras 2 entrevistadas comentaron haber ingresado de manera directa a la cultura otaku, aproximadamente hacía unos 5 años, a través de internet y las redes sociales.

Con respecto a la pertenencia e incursión en un grupo de seguidores solo 2 comentaron no pertenecer a algún grupo de admiradores en específico. Los 8 restantes se desempeñaban 
en diversos grupos sociales incluyendo el de los fanáticos por la cultura asiática y de manera más especial, la japonesa, acudiendo a reuniones anuales, mensuales e incluso semanales. Además, todas las entrevistadas aseguraron acudir a las convenciones realizadas en la ciudad: "No soy parte de ningún club, pero sí me gusta ir a las convenciones, ahí encuentro cosas originales que puedo comprar aunque tampoco voy todos los días que dura..." (Sujeto $3)$.

Solo 3 de estas 8 acuden constantemente a las reuniones donde se efectúan actividades conjuntas con sus grupos como son los cosplays de elección grupal o personal. Acciones que refuerzan la pertenencia al grupo y a la identidad otaku. El sujeto 4 manifiesta su experiencia al respecto:

¡Uy! Cuando yo empecé en esto habíamos muy pocas personas y eran muy pocos los lugares que había donde podías comprar cosas además de que eran muy caras. Me acuerdo que entré al club, porque una vez pasé por plaza Fundadores (Plaza de San Luis Potosí) y estaban unos chavos disfrazados (cosplays) de algunos personajes que no recuerdo en este momento cuáles eran y a mí me encantó. Me acerqué a ellos y les pregunté: qué hacían. Me dijeron que eran un club que se juntaban los fines de semana y que les gustaban las cosas de anime y ya les pregunté si podía ir con ellos y me dijeron que sí. Así que al siguiente fin de semana fui con ellos... Me gustó mucho, porque me sentí muy identificada. Les gustaba lo mismo que a mí y me entendían... Aún sigo viéndolos aunque ya no es igual, porque cada uno tiene cosas que hacer. Ahora también voy a las convenciones que hacen. Antes había solo una al año, pero ahora ya hay más... (Sujeto 4)

Con respecto, a la imagen personal y caracterización con la cultura otaku de las entrevistas arrojaron que existe cierta identificación con alguno de los personajes de las series vistas: "EI anime que me marcó más desde niña fue Los Caballeros del Zodiaco porque ahí aprendí el valor de la amistad y también la lealtad" (Sujeto 4)

Se identifican a través de un físico parecido, ideologías similares, culminación de sueños, metas o situaciones de la vida cotidiana, pero solo la mitad consideró haber cambiado su estilo de vida o la forma de como lucía (maquillaje, peinado, vestuario o indumentaria). 
En el anime "Lovely Complex", Risa Koizumi, la chica más alta de todas, conoce a Atsushi Ootani, el chico más bajo de todos. Esta situación llamó mi atención, ya que en la secundaria yo era precisamente la chica más alta de mi grupo, mientras que uno de mis mejores amigos era el chico más bajo del grupo. A grandes rasgos diré que me enamoré de él, y fui rechazada en múltiples ocasiones con una amplia variedad de argumentos. Cuando comencé a ver la serie, no podía identificarme al 100\% con Risa, porque su amor por Ootani surgió conforme avanzaba la historia. Sin embargo, existían situaciones que me resultaban totalmente familiares. (Sujeto 1)

En la categoría de consumo se encontró que la mayoría de entrevistadas dedican entre seis y diez horas a la semana al uso de productos culturales asiáticos audiovisuales. Los medios predilectos para realizar dicho consumo es internet con su gran variedad de espacios que permiten la descarga gratis de películas o series, la compra física o préstamo de los productos. Con respecto a la música, dedican entre cerca de tres horas diarias, es decir, 21 horas a la semana para buscar videos musicales así como descargar canciones, aunque la tercera entrevistada comentó que sólo veía series en los fines de semana ya que las actividades escolares no le permitían invertir más tiempo y en cuanto al consumo de música o búsqueda de video es variable ya que en ocasiones podía realizar las tareas mientras escuchaba algunas canciones. Por otra parte, el sujeto 7 dijo "que puede invertir unas 6 horas diarias para consumo no sólo en computadora, también en los trayectos de casa al trabajo y del trabajo a la casa", dicho de otro modo, podrían ser de dos a tres horas fuera de casa y otras tres extras en internet, esto sin contar los fines de semana en el cual aprovechan para ponerse al tanto.

Uno de los datos más representativos que arrojó esta investigación es la inversión monetaria de las Otakus ya que 6 de ellas aseguraron tener productos originales traídos de Asia y cuyos precios se encuentran entre los doscientos y mil pesos mexicanos. Al mes destinan por los menos trescientos pesos para darse algunos gustitos (como algunas personas les llaman) llámense discos originales, posters, figuras de colección, etc. Por lo tanto, en un año 6 de las 10 entrevistadas gastan alrededor de 3600 pesos en compras sin contar las entradas a convenciones, realizaciones de cosplays o adquisiciones espontáneas, lo que da 
un total de 21600 pesos en consumo cultural de industrias asiáticas con mayor tendencia japonesa, seguida de la coreana. Así afirman: "... en temporadas donde cuento con más dinero he llegado a gastar 1000 pesos cada 6 meses..." (Sujeto 9)

\section{Aportaciones finales}

A lo largo de esta investigación se ha hablado de las animaciones japonesas y las afinidades por todo lo proveniente de Japón alrededor del mundo, con la creación grupos de aficionados que se sienten más que unos simples admiradores por Japón y su cultura, ya que han adaptado su vida a las costumbres niponas. Pero estos otakus difieren de los otakus japoneses, y se les considera otakus globalizados o Akiba Kei. Para ellos, el cómo se les denomine no tiene importancia siempre y cuando queden claros sus deleites y aficiones.

De igual manera, se ha discutido sobre la identidad de los otakus en México y se devela que se forjan a través de la admiración a los personajes de las animaciones japonesas, así como a sus ideas y modas. Es, en este placer, donde a su vez se genera una identidad grupal y así, se puede decir que se desecha la concepción primaria del otaku como un inadaptado social, ya que es con sus iguales con quienes comparte sus gustos.

Por ello, se puede concluir que pertenecer a la cultura otaku no significa aislarse o abandonar los demás roles que se desempeñan en la sociedad y en la vida diaria, es decir, pueden ser amigos, estudiantes, hijos e incluso padres sin descuidar la parte del hobby 0 gusto por el anime.

Por último, quienes pertenecen a esta cultura distinguirse de los demás no les causa conflicto, siempre y cuando no se les critique su estilo de vida. "Ser Otaku no es algo malo por lo que las demás personas se tengan que asustar o asilar al conocer a alguien así... es alguien con gustos diferentes" (Sujeto 7). 
Esta investigación exploratoria en la identidad otaku mexicana, abre nuevos caminos de indagación como ampliar el espacio geográfico del perfil de los otakus para llevar a cabo una radiografía del fenómeno otaku en México. También se puede plantear indagar en el perfil de los otakus de género masculino; así como, analizar los personajes con los cuales se identifican principalmente en busca en rasgos identitarios carentes en su cultura.

\section{Bibliografía}

Balderrama, L y Pérez, C. (2009). La elaboración del ser Otaku desde sus prácticas culturales, la interacción con el otro y su entorno [versión electrónica]. Recuperado de http://biblioteca2.ucab.edu.ve/anexos/biblioteca/marc/texto/AAR5086.pdf

Cobos, T.L. (2010). Animación japonesa y globalización: la latinización y la subcultura otaku en América latina [versión electrónica], Revista Razón y Palabra. Recuperado de http://www.razonypalabra.org.mx/N/N72/Varia 72/32 Cobos 72.pdf

García Cabrero, Benilde. (2009). Manual de métodos de investigación para las ciencias sociales. Un enfoque de enseñanza basado en proyectos. México: Universidad Nacional Autónoma de México.

Hernández Sampieri, R., Fernández Collado, C., Baptista Lucio, P. (2010). Metodología de la investigación. (5aa ed.). Perú: Editorial McGrawHill.

Margulis, Mario., Barbero, J.M., Pérez, J.A., Pampols, C.F., Perea, C.M., Giberti, Eva., Serrano, J.F., Parra, Rodrigo., Urresti, Marcelo., Valenzuela, J.M., Reguillo, Rossana., Salazar, Alonso., Muñoz, Sonia., Muñoz, Germán., Pérez, J.M. y Marafioti, R.C. (2008). "Viviendo a toda" Jóvenes, territorios culturales y nuevas sensibilidades. Colombia: Siglo del hombre editores.

Reguillo, Rossana (2000) Emergencia de culturas juveniles. Estrategias del desencanto. Bogotá: Norma.

Reguillo, Rossana (1991) En la calle otra vez las bandas: identidad urbana y usos de la comunicación. (2 ${ }^{\underline{a}}$ ed.). ITESO, Guadalajara Jal. México.

\section{Forma de citar este artículo en bibliografías}

GARCÍA NOYOLA, F. I. y GABINO CAMPOS, M.A.(2016): "De Japón para el mundo: consumo y percepción de las jóvenes otakus mexicanas", en Revista PANGEA №7, Volumen № 1, páginas 54 a 68. Tenerife: Red Académica Iberoamericana de Comunicación. Recuperado el __ de de 2 de: http://www.revistapangea.org 